\title{
MIGRACIJSKI PROCES V OMREŽNI DRUŽBI
}

\author{
Blaž LENARČIČ
}

COBISS 1.02

\section{IZVLEČEK}

\section{Migracijski proces v omrežni družbi}

Članek obravnava vpliv rabe informacijsko-komunikacijskih tehnologij na migracijski proces. $\mathrm{V}$ tem smislu poudarja časovno-prostorsko neodvisno delovanje, ki ga te tehnologije omogočajo. Poleg tega, da tovrstno delovanje povzroča prehod od območne k omrežni organizaciji družbe, migrantom omogoča, da fizično oddaljene izvorne domovine emocionalno in družbeno nikoli ne zapustijo, kar se ne sklada z dosedanjim sociološkim portretom migranta. Na teh izhodiščih prispevek med drugim odpira vprašanje o ponovnem premisleku koncepta migranta, in sicer v pogojih omrežne družbe.

KLJUČNE BESEDE: migracijski proces, informacijsko-komunikacijske tehnologije, migranti, omrežna družba

\section{ABSTRACT}

\section{The Migration Process in the Network Society}

The article deals with the impact of the use of information and communication technologies on the migration process. In this context, it gives special emphasis to the individual action independent of time and space which is enabled by these technologies. In addition to the fact that this kind of action causes the transition from the territorial to the network organization of society, it allows migrants never to leave their physically distant homelands emotionally and socially, which is not in line with the current sociological portrait of a migrant. Starting from this premise, the article proposes a reconsidering of the concept of migrant, based on the conditions of the network society.

KEY WORDS: migration process, information-communication technologies, migrants, network society

Dr. sociologije, znanstveni sodelavec, docent, Znanstveno-raziskovalno središče Koper, Garibaldijeva 1, SI-6000 Koper; blaz.lenarcic@zrs-kp.si 


\section{UVOD}

"Yesterday the motto was: immigrate and cut your roots; today it would be: circulate and keep in touch."

(Dana Diminescu, 2008)

Obdobje, v katerem živimo, zaznamuje vrsta sprememb, med katerimi sta gotovo najopaznejša hiter tehnološki napredek in porast medcelinskih migracij. Slednje je pomemben dejavnik preoblikovanja družb po celem svetu, zaradi česar je 21. stoletje označeno kot stoletje migracij. (Goldin, Cameron 2011; Castles, de Haas, Miller 2014) Podobno na družbo vplivajo informacijsko-komunikacijske tehnologije' (IKT), kar se kaže že v pogostosti uporabe pridevnika informacijski pri njenem poimenovanju. V prispevku se ukvarjam z obema procesoma, pri čemer me zanimajo predvsem učinki ključne značilnosti IKT, tj. časovno-prostorsko neodvisno delovanje akterjev $v$ kontekstu migracijskega procesa. $V$ zadnjem času smo namreč priča intenzivnemu napredku pri razvoju in dostopnosti IKT ter storitev, ki uporabnikom, neodvisno od njihove fizične lokacije, omogočajo komuniciranje v realnem času. Na splošni ravni te dinamike povzročajo prehod od območne k omrežni organizaciji družbe, $v$ kontekstu migracij pa od domovine oddaljenim posameznikom omogočajo z njo dokaj intenzivno povezanost. Takšno stanje ni več skladno z uveljavljenim sociološkim portretom migranta, za katerega so značilne zelo omejena komunikacija ali celo trajne prekinitve stikov z osebnimi koreninami ali drugimi posamezniki, ki ga povezujejo z domačim okoljem. Na teh temeljih sta cilja prispevka (1) predstavitev razsežnosti raziskovalnega področja in (2), predvsem v slovenskem prostoru, spodbuditev preučevanja IKT v kontekstu migracijskega procesa.

\section{OD TERITORIALNE K OMREŽNI ORGANIZACIJI DRUŽBENEGA DELOVANJA}

Sociologi (Mlinar 1994; Castells 1996; Wellman 2001; 2004; Barney 2004; Terranova 2004; Lee, Wellman 2012 ipd.) ugotavljajo, da je intenzivna uporaba IKT na vseh področjih vsakdanjega življenja v zadnjih desetletjih ustvarila nov tip družbe, ki ga imenujejo omrežna družba. ${ }^{2}$ Odnosi in procesi v tej družbi temeljijo na načelih omrežij,

1 Za podrobnejšo opredelitev IKT in oris njihove funkcionalnosti v širši družbi glej na primer: Lenarčič (2014; 2010), Bakardijeva (2005), Oblak, Petrič (2005), Trček (2003), Bell, Kennedy (ur.) (2002) in Jordan (1999).

2 Za poimenovanje (današnje) družbe, ki jo zaznamuje uporaba IKT, se je v splošni in (večinoma) tudi v strokovni rabi uveljavila sintagma informacijska družba. Uporaba omenjenega izraza je po mojem mnenju neprimerna, kar utemeljujem na drugem mestu (Lenarčič 2010), zato $v$ pričujočem prispevku uporabljam termin omrežna družba. $V$ prid slednjemu je tudi dejstvo, da so v sociologiji omrežja med najpomembnejšimi pojasnjevalnimi dejavniki migracij (Arango 2004; King 2012; Collin 2015). 
kar jo loči od drugih družbenih oblik. »Omrežja sestavljajo novo družbeno morfologijo naših družb, obenem pa razširjenost logike mreženja močno spreminja delovanje ter rezultate procesov proizvodnje, izkušenj, moči in kulture« (Castells 1996: 469). Čeprav je omrežna organizacija nedvomno obstajala že v prejšnjih družbenih oblikah, pa pred razširjeno rabo IKT mreženje ni potekalo preko celotne družbene strukture, sedaj pa pomembno vpliva na vsa področja družbenega življenja posameznikov. Obširne družbene spremembe, ki izhajajo iz omrežij kot dominantne oblike organizacije, so zelo dobro dokumentirane v velikem številu raziskav, med katerimi nedvomno izstopa Castellsova trilogija The Information age: Economy, society and culture (1996; 1997; 1998), v kateri je utemeljil paradigmo omrežne družbe. Na tem mestu moram pojasniti, da poudarjanje prevladovanja omrežne organizacije nad območno oziroma teritorialno ne pomeni, da so druge oblike družbene organizacije izginile, niti tega, da bodo. Pri tem je bistveno, da vzpon nove organizacijske paradigme močno vpliva na vse družbene segmente, saj preoblikuje referenčni okvir, v katerem delujejo akterji, kar sem podrobneje predstavil v predhodnih delih (npr. Lenarčič 2010a; 2014).

$\checkmark$ prispevku me zanima predvsem časovno-prostorsko neodvisno delovanje akterjev, kar je ključna značilnost omrežne družbe. Na izkustveni ravni takšno delovanje omogoča doživljanje sveta kot manjšega oziroma obvladljivega, kar pomeni, da imajo akterji možnost medsebojnega povezovanja in integriranja v nove prostorsko-časovne kombinacije, ki presegajo teritorialne in nacionalne meje ter omogočajo ubikviteto; določene entitete lahko, neodvisno od časa in prostora, obstajajo kjerkoli in kadarkoli. Posledica tega sta povezovanje dejavnosti in ljudi, ki niso več občutljivi za medsebojno (fizično) oddaljenost, ter posameznikovo preklapljanje med različnimi omrežji. V tem je tudi eden ključnih vzrokov, da so koncepti, povezani z migracijskim procesom, na primer meje, fiksnost, prisotnost ter razdalja, dobili drugačen pomen, kot so ga imeli še pred dvema desetletjema.

Potek te spremembe je na primeru vpliva komunikacijskega procesa na razvoj različnih tipov skupnosti zelo dobro pojasnil Wellman (2001), in sicer je prvo stopnjo komunikacijskega procesa metaforično poimenoval »povezanost od vrat do vrat«. Doseg komunikacije je namreč odvisen od razdalje, ki so jo akterji sposobni premagati s fizičnim premikanjem. Tehnološki razvoj ter večja dostopnost predvsem stacionarnih telefonov in osebnih računalnikov s fiksnim dostopom do interneta sta privedla do druge stopnje razvoja, ki jo avtor poimenuje "povezanost od kraja do kraja«. Komunikacijski pripomočki tega obdobja medsebojno povezujejo akterje na krajih, kjer so nameščeni, zaradi česar Wellman (prav tam) to obliko omrežij imenuje tudi »glokalna povezanost«. Danes prevladujejo brezžični komunikacijski pripomočki, kar pomeni, da jih uporabniki nosijo s seboj. S tem jim je omogočeno komuniciranje kjerkoli in kadarkoli, kar na potencialno globalni ravni po Wellmanu (prav tam) ustvarja "povezanost od osebe do osebe«, katere ključna značilnost je, da so posamezniki kljub fizični oddaljenosti nenehno povezani s svojim socialnim omrežjem. 
Takšna potencialno neomejena svoboda stikov je med drugim povzročila osvoboditev od interakcij, ki temeljijo (zgolj) na fizičnih krajih, in v ospredje postavila samo komunikacijo. O zmanjševanju pomena fizične lokacije v kontekstu komunikacije med posamezniki je sredi osemdesetih let prejšnjega stoletja pomembna opažanja podal že Meyrowitz: »Kot vsi elektronski mediji tudi telegraf ne zgolj, da definira meje, ki jih je postavila razdalja, ampak zaobide tudi družbene obrede prehoda, to je dejanje fizičnega in družbenega premikanja iz ene pozicije do druge« (Meyrowitz 1985: 116). Povedano z drugimi besedami, v današnjem času smo priča procesu vzpostavljanja dokaj ostre ločnice med fizičnim in družbenim prostorom. In sicer gre za razlikovanje med so-lokacijo, katere temelj je prostorsko razmerje med akterji in so-prisotnostjo (Zhao 2003), ki temelji na družbenem odnosu med akterji. So-prisotnost med drugim pred izziv postavlja predpostavko, da tesni medosebni odnosi med posamezniki zahtevajo fizično bližino, kar je še zlasti aktualno v kontekstu migracijskega procesa.

Komunikacija preko IKT v vsakdanje življenje migrantov prinaša pomembne spremembe tako v kvalitativnem kot tudi kvantitativnem smislu. V zvezi s tem $\mathrm{Ne}$ delcu (2012) v analizi romunskih migrantov v Kanadi ugotavlja, da te tehnologije omogočajo pojav »transnacionalne vsakdanje realnosti«, ki temelji na vseprisotnosti, simultanosti in neposrednosti interakcij na daljavo. Na takšen način posamezniki, ki so fizično oddaljeni od domovine, kljub temu ostajajo povezani z njo, saj jim tehnologija omogoča vzdrževanje »transnacionalnih omrežij« socialne in čustvene opore, spremljanje kulturnih tradicij, konzumiranje različnih materialnih in nematerialnih elementov izvorne kulture ipd. V določenem smislu te tehnologije delujejo kot »družbeno lepilo«, ki migrante povezuje z izvorno kulturo, družinami in s prijatelji. Vendar kljub temu da predstavljene dinamike pomembno vplivajo na migracijski proces, preučevanje IKT v kontekstu migracij med raziskovalci do nedavnega ni vzbujalo večje pozornosti.

\section{PREUČEVANJE INFORMACIJSKO-KOMUNIKACIJSKIH TEHNOLOGIJ V KONTEKSTU MIGRACIJ}

V nasprotju z drugimi klasičnimi sociološkimi koncepti (npr. s skupnostjo, z nacionalno državo, s prostorom, z identiteto, neenakostjo ipd.), katerih preučevanje je potekalo bolj ali manj vzporedno z razvojem IKT, za migracijski proces tega ne moremo trditi. Preučevanje tega procesa v kontekstu IKT se je namreč začelo hitreje razvijati 
šele v zadnjem desetletju. ${ }^{3}$ Takšno razvojno zamudo lahko pripišemo vsaj dvema dejavnikoma, ki ju v svoji študiji poudarijo Brokert idr. (2009). Avtorji najprej ugotavljajo, da je bila pozornost raziskovalcev izrazito usmerjena na vpliv, ki ga imajo IKT zgolj na določene skupine migrantov, kot so intelektualne elite in visoko kvalificirani posamezniki (npr. Florida 2007; 2002; Hamel 2009), medtem ko je bila večinska populacija migrantov ob preučevanju vplivov IKT zapostavljena zaradi razširjenosti predsodka, da je za rabo tovrstnih tehnologij manj izobražena.

Kot drugi vzrok razvojnega zaostanka preučevanja IKT v kontekstu migracij Brokert idr. (2009) navajajo splošne značilnosti akademske skupnosti, in sicer ima po njihovih ugotovitvah veliko predvsem družboslovnih raziskovalcev zgolj površinsko znanje in razumevanje delovanja in učinkov IKT na odnose in procese v družbi. Posledično prihaja do pomankanja sposobnosti analiziranja z njimi povezanih fenomenov. Če torej želimo razumeti sodobne družbeno-kulturne kompleksnosti migracijskega procesa, je, kot ugotavlja Halilovich (2013), treba konvencionalne raziskovalne pristope razširiti (tudi) v kibernetski prostor. Preseganje (še vedno) relativno ostre ločnice med družbenimi procesi in odnosi, ki potekajo $v$ fizičnem in kibernetskem prostoru, je v današnjem obdobju nujno, saj se prepletajo in so medsebojno odvisni. Med ključnimi posledicami prepletanja obeh prostorov je, metaforično rečeno, tudi to, da je posameznik postal portal (Wellman 2000) oziroma stikalo, ki preprosto preklaplja med posameznimi omrežji, kar pomembno vpliva na izkustvo družbene realnosti, $v$ kateri se $v$ realnem času odvijajo interakcije med akterji, ki si ne delijo skupnega (fizičnega) prostora. Takšno stanje zahteva določene spremembe $v$ pojasnjevanju družbenih dinamik, ki so bile do sedaj večinoma razumljene in interpretirane (zgolj) $v$ razmerah fizične oddaljenosti, med katere nedvomno sodi tudi migracijski proces.

Kot sem že omenil, se stanje pri preučevanju migracij v kontekstu IKT v zadnjem desetletju izboljšuje, kar potrjujejo tudi pregledi znanstvene literature, ki so jih opravili Brokert idr. (2009), Kozachenko (2013) in Collin idr. (2015). Vsi avtorji ugotavljajo, da je pomen teh tehnologij $v$ kontekstu migracij že dokaj prepoznan, kljub temu pa to področje še vedno trpi zaradi teoretskih in metodoloških (Vancea, Boso 2014) pomanjkljivosti. V zvezi s tem navajam Mlinarja (1994), ki je že pred časom v svoji razpravi o vplivu IKT na odnose in procese $v$ fizičnem prostoru opozarjal, da je naša miselnost še močno zakoreninjena v starih, preživelih predstavah o območni prostorski organizaciji družbe. V kontekstu migracijskega procesa so podobno razmišljali tudi

3 Pregled literature na temo migracijskega procesa in IKT je pokazal, da med slovenskimi raziskovalci ta tema ni aktualna. Do sedaj sta se s to tematiko ukvarjali Erjavec (2013) in Zelenik (2018), ki sta preučevali učinke uporabe IKT na mlade posameznike, ki živijo v Sloveniji, izvirajo pa iz republik nekdanje Jugoslavije. Medtem ko se avtorji drugih dostopnih raziskav (Čikić 2002; Meden 2007; Mikola, Gombač 2008; Milharčič Hladnik 2017) ukvarjajo z analizo uporabe IKT med slovenskimi izseljenci po svetu, pri čemer jih zanima predvsem uporaba tehnologij pri ohranjanju, razvijanju in spreminjanju povezanosti med ljudmi, ki jih družita isto poreklo in želja ohranjati svojo etnično identiteto. Na tem mestu je treba omeniti tudi prispevek Zavratnikove in Cukut Krilićeve (2018), ki obravnavata intersekcije med digitalnostjo in begunskimi potmi, pri čemer se osredotočata na koncepta »povezanih migrantov« in digitalnih odtisov begunskih poti v transnacionalnih prostorih. 
Massey idr. (1998), in sicer izhajajo iz tega, da migracije koreninijo v posebnih zgodovinskih razmerah, ki opredeljujejo točno določen družbeni in ekonomski kontekst. To pomeni, da današnjega migracijskega procesa ne moremo pojasnjevati in razlagati s starimi koncepti.

Teoretični koncepti, ki jih sedaj družboslovci uporabljajo za analizo in razlago mednarodnih migracij, so bili oblikovani predvsem v industrijskem obdobju in odražajo njegove posebne gospodarske ureditve, družbene institucije, tehnologijo, demografijo in politiko. Te teorije iz industrijskega obdobja so povzročile nastanek konceptualnega ogrodja, ki se je obdržalo desetletja. Čeprav je bilo ob nastanku tekoče in kreativno, je sčasoma postalo togo in se zdi neprimerno za popolnoma drugačne razmere poznega 20. stoletja. [...] Klasični pristop je zdaj vstopil v stanje krize, saj ga spodbijajo nove ideje, koncepti in hipoteze. (Massey idr. 1998: 3)

Skratka, IKT so neločljivi del današnje (razvite) družbe, in prav tako kot brez upoštevanja tehnološke dimenzije ni mogoče razumeti trenutnih ekonomskih, političnih in kulturnih sfer, ni mogoče razumeti tudi sodobnega migracijskega procesa.

Tukaj je treba poudariti, da je empirično preučevanje IKT v kontekstu migracijskega procesa izjemno kompleksno, migranti namreč simultano pripadajo različnim sociodemografskim in pravnim kategorijam. Poleg tega je treba upoštevati tudi druge dejavnike, kot na primer generacijsko pripadnost in stopnjo njihove digitalne pismenosti, navsezadnje pa tudi socialne, emocionalne in moralne vidike migrantov, kar vse vpliva na odločitev za uporabo določenega komunikacijskega medija. (Madianou, Miller 2012) Pri tem je ključnega pomena, da namen in uporaba IKT med migranti variirata glede na stopnjo migracijskega procesa oziroma, kot to poimenujeta Hiller in Franz (2004), faze migracijskega cikla. In sicer avtorja ločujeta 'predmigrantsko' (pre-migrant), 'postmigrantsko' (post-migrant) in 'ustaljeno' (settled migrant) fazo migracijskega procesa. V nadaljevanju predstavljam uporabo IKT v vsaki od treh faz, dodal pa sem jim še fazo potovanja, ki glede na kronološki potek migracijskega cikla sodi na drugo mesto.

V predmigracijski fazi posameznik s pomočjo IKT išče informacije, ki so relevanthe pri sprejemanju odločitve za migriranje in za samo potovanje. Te tehnologije so mu v pomoč tudi pri vzpostavljanju stikov s posamezniki in skupnostmi v destinacijski državi, z namenom zagotavljanja pomoči pri namestitvi, zaposlitvi ipd. V tej fazi so IKT pomemben pripomoček tudi za ilegalne migrante, saj jim omogočajo samostojno načrtovanje potovanja, s čimer se izognejo posrednikom in tihotapcem. V predmigracijski fazi so IKT tudi pomemben »dejavnik potiska« migracij, saj se $z$ njihovo pomočjo $v$ državah $v$ razvoju ustvarjajo idealnotipske podobe razvitih držav (Appadurai 1996), in to predvsem s pozitivnimi vsebinami, ki jih na različnih spletnih aplikacijah objavljajo migranti in delujejo kot pritisk na vrstnike, ki so ostali v domovini, da tudi oni odidejo (Nimo llhan 2016). Po drugi strani pa Hunter (2006) v empirični raziskavi, izvedeni med Jamajčani, ugotavlja, da družinski člani in prijatelji migrantov 
v njihovi domovini preko pogostih stikov, ki jih omogočajo IKT, dobivajo realnejše podobe destinacijskih držav in migracijske izkušnje, kar je vzrok za opustitev lastnih selitvenih načrtov. Z namenom odvračanja migrantov nekatere države uporabljajo tudi možnosti antipropagande, ki jih nudijo IKT. Tako je na primer avstralska vlada ustvarila serijo kratkih videov ${ }^{4}$ ki se kot oglasna sporočila pojavljajo na aplikaciji YouTube, $v$ njih pa uniformirani pripadniki mejne policije svarijo potencialne ilegalne migrante, naj ne poskušajo prebežati v njihovo državo, ker jih bodo zajeli. Tovrstna sporočila se prikažejo na osnovi algoritma, ki z upoštevanjem kombinacije določenega tujega jezika (npr. Dari) in lokacije, ki je opredeljena kot tranzitna (npr. Indonezija), v spletnem uporabniku prepozna potencialnega migranta.

$V$ fazi potovanja so IKT navigacijsko in komunikacijsko orodje, ki ga uporabljajo predvsem ilegalni migranti. Kot v svojih študijah poudarjajo Frouws idr. (2016) ter Zijlstra in Van Liempt (2017), ilegalni migranti med potovanjem spletne aplikacije, kot so Facebook, Twitter, Skype, Viber, WhatsApp, Google Maps ipd. uporabljajo predvsem za iskanje varnih poti ter točk za prečkanje meja, ki jih ne nadzoruje policija, medsebojno komuniciranje, pregledovanje vremenskih napovedi ipd. Poudariti pa je treba, da IKT uporabljajo tudi institucije, ki se ukvarjajo tako z nadzorovanjem kot nudenjem pomoči migrantom. Pri tem imam v mislih predvsem policijo (npr. prisluškovanje pogovorom, biometrične vize ipd.) ter nevladne organizacije za pomoč beguncem, ki so se na poti znašli v težavah. ${ }^{5}$

Uporabi IKT in njenim učinkom v postmigrantski in ustaljeni fazi migrantskega cikla se podrobneje posvečam $v$ naslednjem poglavju, zato na tem mestu navajam zgolj ključne informacije, potrebne za njihovo razumevanje. In sicer je v postmigrantski fazi potovanje končano, posameznik pa je v destinacijski državi vsaj pet let. To je obdobje, ki je za Hillerja in Franza (2004) arbitrarni časovni okvir, v katerem se migrant prilagodi življenju v novem družbeno-kulturnem okolju. Medtem ko je v ustaljeni fazi (preseganje petletnega obdobja) po njunem mnenju migrant navadno že prilagojen novemu okolju in poskuša ponovno odkriti izgubljeno povezavo ali obdržati vez z domovino. Ključno pri tem je, da migranti v obeh fazah uporabljajo IKT, in sicer kot pripomoček za integracijo v novo družbeno okolje in kot sredstvo za ohranjanje stikov z ljudmi in s kulturo iz domovine.

Iz predstavljene uporabe IKT v posameznih fazah migracijskega cikla je razvidno, da gre pri tem za precej široko in razvejano raziskovalno področje. Obenem pa je

4 Na primer: https://www.youtube.com/watch?v=rT12WH4a92w (15. 8. 2018).

5 Nevladna organizacija Migrant Offshore Aid Station z Malte je na primer leta 2016 uporabila drone, s pomočjo katerih so iskali in reševali begunce brodolomce v Sredozemskem morju. Kot rezultat begunske krize v Siriji leta 2015 so se Googlovi prostovoljci povezali z organizacijama International Rescue Comittee in Mercy Corps ter za prebežnike zasnovali krizno informacijsko središče Refugee.Info, ki zagotavlja ključne informacije o varnem gibanju, zakonitih pravicah in zanesljivih storitvah beguncem v Grčiji ter balkanskih državah. Podobno aplikacijo z imenom MigApp ponuja tudi International Organization for Migration, s katero beguncem zagotavlja zanesljive in preverjene informacije o storitvah, ki so jim na voljo $v$ posameznih državah (npr. postopek za pridobitev vize, pravila o prečkanju meje ipd.). 
tudi jasno, da te tehnologije pomembno spreminjajo dosedanjo migracijsko izkušnjo in posledično vplivajo tudi na samo razumevanje koncepta migranta. Slednje nekateri avtorji že prepoznavajo, sodobne migrante označujejo s sintagmami, kot so povezani migrant (Diminescu 2008), on-line migrant (Nedelcu 2009), mediatizirani migrant (Hepp idr. 2012), transnacionalni migrant (Lingel, Naaman, boyd 2014) ipd.

\section{OD UKORENINJENEGA K POVEZANEMU MIGRANTU}

Za migrante je bilo ohranjanje stikov s sorodniki in prijatelji iz domovine do nedavnega velik izziv. Predvsem draga sinhrona (telefon) in počasna asinhrona (pismo) komunikacijska sredstva so tako v kvalitativnem kot kvantitativnem smislu močno vplivala na stike z domovino in ljudmi, ki so ostali v njej. Kot opozarjata Hiller in Franz (2004), so se prav iz te situacije razvili termini, kot so »izkoreninjeni« in »presajeni« migrant ter »kulturni šok«. Sčasoma sta razvoj in dostopnost IKT privedla do časovno-stroškovne ugodne sinhrone in asinhrone komunikacije. V praksi to pomeni, da so migranti preko IKT lahko v nenehnem stiku z domovino in diasporo, obenem pa so zanje te tehnologije uporabno orodje za pridobivanje raznovrstnih formalnih ${ }^{6}$ in neformalnih informacij o vsakdanjem življenju (kulturi, religiji, političnih zadevah ipd.), izobraževanju (jeziku, kulturi ipd.) ter specifičnih težavah, s katerimi se srečujejo (za bivanje potrebni dokumenti, zdravstvena zavarovanja, zakonodaja ipd.). Z namenom lažje izmenjave informacij ter izražanja domovinskih čustev migranti na spletu ustanavljajo tudi (virtualne) skupine, kot so na primer Facebook strani Slovencev, ki živijo v različnih državah po svetu. ${ }^{7}$ Omenjene spletne strani sedaj opravljajo funkcijo etničnih vasi, delujejo namreč kot kratkoročni mehanizmi prilagajanja (npr. izmenjava informacij) migrantov novi kulturi in destinaciji, obenem pa preko njih tudi vzdržujejo stik z domovino oziroma njeno kulturo.

Predstavljene dinamike v kontekstu migracijskega procesa kažejo, da uveljavljene dihotomije prisoten/odsoten, domovina/tujina, blizu/daleč ipd. niso več relevantne, saj IKT s svojo logiko delovanja, ki ni odvisna od časa in prostora, uvajajo vmesne možnosti. To vodi k odmiku od dosedanjega razumevanja migrantov kot posameznikov, ki so pretrgali vezi z matično domovino in so ukoreninjeni v novo družbeno okolje, ter vpeljuje koncept migranta, ki ima z izvorno deželo nenehne stike in je v njej so-prisoten (Zhao 2003). Povedano drugače, IKT migrantu omogočajo, da se nahaja v vmesnem prostoru, kar pomeni, da ni ne tu ne tam, ampak hkrati tu in tam.

6 Nemčija je npr. vzpostavila aplikacijo Ankommen (http://ankommenapp.de/), ki migrantom in prosilcem za azil ponuja osnovni tečaj nemškega jezika, informacije v zvezi z azilnim postopkom, pomoč pri iskanju zaposlitve in izobraževanju, navsezadnje pa tudi informacije o nemških vrednotah in običajih.

7 Na dan 24. 8. 2018 je iskalnik na Facebooku na podlagi ključne besede »Slovenci« izpisal imena 92 skupin, v katere se združujejo Slovenci, živeči v različnih državah po svetu. 
Današnji migrant je predstavnik nove kulture mobilnosti, ki združuje mednarodno geografsko mobilnost in digitalno mobilnost. Kljub razdalji načini povezovanja omogočajo neprekinjeno so-prisotnost, kar vznemirja klasično sociološko interpretacijo migranta v razmerah »dvakratne odsotnosti«: odsotnosti od doma in odsotnosti primerne integracije v destinacijski državi. (Brokert idr. 2009: 9)

Opisano stanje je, če uporabim Diminescujin (2008) pojasnjevalni aparat, zelo spremenilo migrantsko izkušnjo. Gre za prehod od ukoreninjenega k povezanemu migrantu, IKT današnjim migrantom omogočajo skoraj neomejeno simultano prisotnost $v$ dveh kulturnih kontekstih, in sicer v fizično oddaljeni domovini in državi, $v$ kateri dejansko živijo. Podobno razmišlja tudi Portes (2001), in sicer, da današnji migranti z uporabo IKT lahko simultano živijo $v$ dveh svetovih, tj. domovini in državi, $v$ katero so migrirali. $\vee$ nasprotju s trenutnim stanjem je bilo $v$ razmerah omejene mobilnosti utemeljeno pričakovanje, da ločitev od izvornega kraja pomeni tudi vzpostavitev novega načina življenja in novih socialnih vezi oziroma integracijo v novo okolje. (Mlinar 1997; Hiller, Franz 2004) Sedaj pa logika delovanja omrežne družbe vse bolj zmanjšuje realnost takšne predpostavke, ker, metaforično povedano, IKT migrantu med drugim omogočajo, da na nek način lahko kadarkoli odide domov, obenem pa tudi dom pripeljejo $k$ njemu. Takšno »sinhroniziranje« $z$ domačim krajem in izvorno kulturo pomeni, da sodobni migranti domovine emocionalno in družbeno nikoli ne zapustijo. Povezani migrant torej ni ukoreninjen v novo okolje, ampak je $v$ domovini so-prisoten preko konstantnih stikov $z$ ljudmi in $s$ kulturo, nahaja se $v$ nekakšnem vmesnem prostoru. »Ljudje so tukaj in tam [...] v neizprosni kombinaciji krajev. [...] kraji še vedno obstajajo, vključno z domovi in delovnimi prostori, ampak kot točke konvergence v komunikacijskih omrežjih [...]« (Castells idr. 2007: 127). Za sodobne migrante domovina in ljudje, ki so jih v njej pustili, niso več zgolj spomin, ki ga ohranjajo z redkimi priložnostnimi stiki. Ravno obratno, zaradi možnosti, ki jih nudi uporaba IKT, domovina vedno bolj (p)ostaja pomemben del njihovega vsakdanjega življenja tako pri izmenjavi emocionalnih, ekonomskih in socialnih virov kot tudi pri oblikovanju kulturne identitete.

\section{TRANSNACIONALNI ŽIVLJENJSKI STIL MIGRANTOV}

Hkratno prepletanje družbenih dinamik dveh ali več medsebojno fizično in kulturno oddaljenih krajev, ki ga sodobnim migrantom omogočajo IKT, za potrebe te razprave označujem s sintagmo »transnacionalni življenjski stil«. Po Smithu (2001) transnacionalnost vztraja na pomenu meja, državnih politik in nacionalnih identitet, čeprav jih pogosto prestopajo komunikacijski tokovi in družbene prakse. Intenzivnost slednjih se je povečala s pojavom komunikacije od osebe do osebe (Wellman 2001), ko so $v$ širšo uporabo prišle prenosne komunikacijske naprave, ki omogočajo stroškovno ugodne interakcije od kjerkoli in kadarkoli. S tem se je namreč uveljavil življenjski stil 
stalne prisotnosti na internetu (boyd 2012), kar je med drugim prineslo povečano frekvenco interakcij med družinskimi člani, sorodniki in prijatelji. Poleg tega so se $\checkmark$ zadnjem času uveljavile tudi aplikacije za povezovanje posameznikov (npr. Facebook, Twitter, Instagram, WhatsApp ipd.), ki uporabnikom omogočajo deljenje različnih medijskih formatov (fotografij, glasu, video posnetkov ipd.), s čimer je komunikacija na daljavo presegla omejitve, povezane s prejšnjimi mediji (npr. pismom in telefonom), saj je v smislu posredovanja informacij postala veliko bogatejša. ${ }^{8}$ Takšne komunikacijske razmere so podlaga za razvoj transnacionalnega življenjskega stila migrantov, ki obsega konstantne vezi in interakcije med posamezniki ter njihovo izvorno kulturo, kar pomeni, da temelji na kulturni in ne na geografski/teritorialni dimenziji. Pri tem je tudi bistveno, da se posamezniki zavedajo dejanj, občutenj in dnevnih dinamik fizično oddaljenih pomembnih drugih. $V$ praksi se ta pojav kaže kot »[...] rastoče število ljudi, ki živijo dvojna življenja, govorijo dva jezika, imajo dom v dveh državah [...] (Portes idr. 1999: 217)

Podrobnejši vpogled $v$ transnacionalni življenjski stil migrantov dajejo empirične študije, izvedene na primerih migrantskih družin (Baldassar idr. 2016; Baldassar, Merla (ur.) 2014; Robertson, Wilding, Gifford 2016). Ugotovitve avtorjev kažejo, da so medsebojno fizično oddaljeni člani družin so-prisotni s pomočjo IKT in tako živijo družinsko življenje. »Klici so tako pogosti, da delujejo kot opomniki na prisotnost drugega, ko ljudje dejansko niso skupaj« (Licoppe, Smoreda 2006: 944). S tem med fizično oddaljenimi družinskimi člani krožijo kulturni, emocionalni, ekonomski in socialni viri. Takšne dinamike vsakdanjega življenja migrantov se odvijajo tudi zunaj družinske sfere, $v$ širših socialnih krogih, kjer so-prisotnost prispeva k vzdrževanju občutka pripadnosti in nudi medsebojno pomoč in oporo. $V$ tem kontekstu je kot hevristično sredstvo $v$ literaturi pogosto uporabljen koncept socialnega kapitala, pri čemer gre za razlikovanje med vezivnim in premostitvenim socialnim kapitalom. ${ }^{9} \mathrm{~V}$ kontekstu uporabe IKT med migranti se vezivni socialni kapital nanaša na uporabo tehnologij z namenom ohranjanja in poglabljanja obstoječih stikov iz izvorne domovine

$8 \quad$ Na tem mestu je treba omeniti teorijo 'polimedijev' (polymedia), s katero Madianou in Miller (2012) pojasnjujeta uporabo določenega medija v danem družbenem, kulturnem, psihološkem in ekonomskem kontekstu. Gre torej za način, kako uporabniki IKT izkoriščajo prednosti teh tehnologij z namenom upravljanja medsebojnih odnosov. Pri tem je bistveno, da komunikacijo med uporabniki oblikujejo lastnosti, ki jih ima določen medij. Na primer tekstovno sporočilo, poslano po telefonu (SMS ali MMS), ne more prenesti neverbalnih znakov oziroma telesne govorice, ta pa se lahko prenese po video komunikaciji (npr. Skypu).

9 Po Gittelu in Vidalu (1998) se vezivni socialni kapital nanaša na koristi (varnost, podporo), ki jih ima posameznik od vključenosti v neko skupino, ali na širše medsebojne odnose (družina, sorodstvo, verske skupine ipd.). V tem primeru gre za socialni kapital na individualni ravni, ki ima tri funkcije, in sicer je vir: družbenega nadzora (solidarnost, zaupanje in norme), družinske podpore in koristi zunaj družinskih omrežij (dostopnost zaposlitve, mobilnost, podjetniški uspeh). Za ta tip socialnega kapitala so značilne močne vezi (Granovetter 1973). Premostitveni socialni kapital pa Gittel in Vidal (prav tam) opredelita kot koristi (dostop do različnih virov informacij), ki jih posamezniku prinašajo šibke vezi (Granovetter 1973). V tem primeru gre za vezi med heterogenimi posamezniki, za katere je po Putnamu (2000) verjetneje, da so bolj krhke, vendar po drugi strani krepijo družbeno vključenost. 
ali države bivanja, medtem ko se premostitveni socialni kapital nanaša na ustvarjanje novih stikov s posamezniki iz države bivanja in diasporo. Premostitveni socialni kapital je pomemben predvsem z vidika integracije v novo družbeno okolje, čeprav Alencar (2018) opozarja, da migranti zaradi uporabe IKT postajajo vse manj odvisni od vzpostavljanja stikov s prebivalci novega družbenega okolja, zaradi česar naj bi te tehnologije zavirale proces njihovega vključevanja.

Predstavljene dinamike pomembno vplivajo tudi na oblikovanje identitete migranta, saj je po IKT v intenzivnem stiku s svojo kulturo, ne da bi bil v njej fizično prisoten. To odseva tudi v pregledu literature, kjer različni avtorji (Borkert idr. 2009; Bradatan idr. 2010; Tsuda 2012; Kozachenko 2013) poudarjajo pomen simultane identifikacije in občutka pripadnosti migrantov dvema ali več državam. Če je do nedavnega proces oblikovanja kulturne identitete migrantov temeljil na interakcijah, ki so potekale $v$ fizičnem prostoru ali pa so vključevale tiskane in elektronske medije, je logika delovanja IKT ustvarila nove socialne situacije, $v$ kontekstu katerih je treba ta proces ponovno interpretirati. Kot pravi Giddens (1991), so za moderno družbeno življenje značilni reorganizacija časa in prostora kot tudi mehanizmi izkrivljanja, ki radikalizirajo in globalizirajo predhodno vzpostavljene institucionalne značilnosti modernosti ter delujejo $v$ smeri preoblikovanja vsebin in narave vsakdanjega družbenega življenja. $V$ tem smislu transnacionalni življenjski stil pomeni, da migranti nenehno prejemajo impulze, ki jih opominjajo na njihov izvor in v vsakdan vnašajo različne kulturne elemente iz domovine, ki se prepletajo $s$ kulturo, $v$ kateri živijo. Takšno stanje ima določene posledice, in sicer, kot pravita Diminescu in Loveluck (2014), migranti pretakajo dva ali več družbeno-kulturnih prostorov, kar vodi v trajni kompleksni proces medsebojnega vplivanja, premikajočega se težišča moči znotraj sebstva in nihajočih odnosov z različnimi skupnostmi. Posledično se migranti navadno čutijo povezane tako $z$ domovino kot $z$ državo, $v$ kateri živijo, kar izključuje identitetno opredeljevanje $v$ smislu »ali-ali« in uvaja prostor za vmesne alternative, kot so transkulturne (Welsh 1995) in mešane (Sedmak, Zadel 2015) identitete.

\section{SKLEPNE MISLI}

V prispevku sem pokazal, da so IKT v veliki meri spremenile migracijsko izkušnjo, zaradi česar jo je nujno treba ponovno premisliti, in to v pogojih (omrežne) družbe. Sodobni migranti namreč poosebljajo kompleksni družbeni hibrid, ki ga je ustvarila kombinacija mobilnosti in uporabe IKT. Ključna značilnost današnjih migrantov je, da so $z$ uporabo IKT nenehno $v$ stiku z izvorno kulturo in ljudmi v domovini. Izhajajoč iz tega lahko rečem, da o migracijah ne moremo več govoriti kot o enosmernem premiku med krajem $A$ in krajem $B$, ampak ga zaradi konstantne izmenjave interakcijskih tokov med obema krajema obravnavamo kot proces, ki sočasno poteka $v$ fizičnem in kibernetskem prostoru. V tem smislu Nedelcu (2012) ugotavlja, da je današnji migrant idealnotipski akter 21 . stoletja, ki je sposoben razviti in obvladovati 
nove geografije vsakdanjega življenja in, kot pokažem v prispevku, pred izziv postaviti vzorce, ki temeljijo na območni organizaciji družbe.

V sklopu obravnavane tematike je pomembna tudi vloga, ki jo imajo IKT pri vključevanju migrantov v širšo družbo. Zaradi omejenosti prostora tej temi v prispevku ne posvečam posebne pozornosti, kljub temu pa moram poudariti, da je tehnološka vključenost migrantov pomembna prav tako kot socialna, politična in ekonomska (Diminescu 2008; Kluzer, Rissola 2009; Khorshed, Imran 2015). Pri tem je treba upoštevati, da so ključne migrantske destinacije predvsem razvite zahodne družbe, v katerih pa je prvi pogoj za posameznikovo polnopravno vključenost prav njegova digitalna pismenost.

V kontekstu obravnavane teme bi bilo treba primerjati migracijske izkušnje v obdobju pred razširjenostjo uporabe IKT in v današnjem času. Takšna študija bi bila precej obsežna in kompleksna, obenem pa tudi dobrodošla. Empiričnih raziskav, ki bi se ukvarjale s tovrstno primerjavo, namreč nisem zasledil, zato bi se bilo tej tematiki tako na mednarodni kot tudi na nacionalni ravni treba posvetiti v prihodnosti.

\section{LITERATURA}

Alencar, Amanda (2018). Refugee Integration and Social Media: A Local and Experiential Perspective. Information, Communication \& Society 21/11, 1588-1603.

Appadurai, Arjun (1996). Modernity at Large: Cultural Dimensions of Globalization. Minneapolis: University of Minnesota Press.

Arango, Joaquin (2004). Theories of International Migration. International Migration and the New Millennium (ur. Danielle Joly). Aldershot: Ashgate, 15-36.

Bakardijeva, Maria (2003): Internet Society: The Internet in Everyday Life. London: SAGE. Baldassar, Loretta, Merla, Laura (ur.) (2014). Transnational Families, Migration, and the Circulation of Care: Understanding Mobility and Absence in Family Life. New York: Routledge.

Barney, Darin (2004). The Network Society. Cambridge: Polity Press.

Bell, David, Kennedy, Barbara (ur.) (2002). The Cybercultures Reader. Second edition. London: Routledge.

Boyd, Danah (2012). 'Participation in the Always on Lifestyle'. The Social Media Reader (ur. Michael Mandiberg). New York: NYU Press.

Bradatan, Christina, Popan, Adrian, Melton, Rachel (2010). "Transnationality as fluid social identity". Social Identities: Journal for the Study of Race, Nation and Culture 16/2, 167-178.

Brokert, Maren idr. (2009). Study on the State of the ar Tof Research in the EU on the Uptake and Use of ICT by Immigrants and Ethnic Minorities. IMISCOE Working paper No. 27. Forum Internazionale ed Europeo di ricerco sull immigrazione international and European forum on Migration research, http://ipts.jrc.ec.europa.eu/ publications/pub.cfm?id=2560 (9. 10. 2018). 
Castells, Manuel (1996): The Rise of the Network Society: The Information Age: Economy, Society and Culture. Vol. I. Oxford: Blackwell Publishing.

Castells, Manuel (1997): The Power of Identity. Vol. Il. Oxford: Blackwell Publishing.

Castells, Manuel (1998). The Information Age: Economy, Society and Culture. Vol. III. Oxford: Blackwell Publishing.

Castells, Manuel idr. (2007). Mobile Communication and Society: A Global Perspective. Cambridge: MIT Press.

Castles, Stephen, de Haas, Hein, Miller, Mark (2014). The Age of Migration: International Population Movements in the Modern World. Fifth Edition. New York: Palgrave Macmillan.

Collin, Simon, Karsenti, Thierry, Calone, Olivier (2015). Migrant`s Use of Technologies: An Overview of Research Objects in the Field. Journal of Technologies and Human Usability 10/3-4, 15-29.

Čikič, Sanja (2002). Povezovanje Slovencev po svetu s pomočjo interneta: Vzpostavljanje virtualnih etničnih skupnosti. Dve domovini / Two Homelands 16, 81-98.

Diminescu, Dana (2008). The Connected Migrant: An Epistemological Manifesto. Migrants and Clandestinity 47/4, 565-579.

Diminescu, Dana, Loveluck, Benjamin (2014). Traces of Dispersion: Online Media and Diasporic Identities. Crossings: Journal of Migration and Culture 5/1, 23-39.

Erjavec, Karmen (2013). Vloga interneta pri integraciji mladih priseljencev iz držav nekdanje Jugoslavije v slovensko družbo. Dve domovini / Two Homelands 37, 7-20.

Florida, Richard (2002). The Rise of the Cerative Class. And how it's Transforming Work, Leisure, Community and Everyday Life. New York: Basic Books.

Florida, Richard (2007). The Flight of the Creative Class. The New Global Competition for Talent. New York: Harper Collins.

Frouws, Bram idr. (2016). Getting to Europe the 'WhatsApp' Way. The Use of ICT in Contemporary Mixed Migration Flows to Europe. Regional Mixed Migration Secretariat Briefing Paper 2.

Giddens, Anthony (1991). Modernity and Self-identity: Self and Society in the Late Modern Age. Cambridge: Polity Press.

Gittel, Ross, Vidal, Avis (1998). Community Organizing: Building Social Capital as a Development Strategy. London: Tousand Oaks, SAGE.

Goldin, Ian, Cameron, Geoffrey (2011). Exceptional People: How Migration Shaped our World and Will Define our Future. Princeton, Oxford: Princeton University Press.

Granovetter, Mark (1973). The Strenght of Weak Ties. American Journal of Sociology 78/6, 1360-1380.

Halilovich, Hariz (2013). Bosnian Austrians: Accidental Migrants in Trans-local and Cyber Spaces. Journal of Refugee Studies 26/4, 524-540.

Hamel, Jean Yves (2009). Information and Communication Technologies and Migration: Human Development Research Paper, http://hdr.undp.org/sites/default/ files/hdrp_2009_39.pdf (15. 1. 2019). 
Hepp, Andreas, Bozdag, Cigdem, Suna, Laura (2011). Mediatized Migrants: Media Cultures and Communicative Networking in the Diaspora. Migrations, Diaspora, and Information Technology in Global Societies (ur. Leopoldina Fortunati, Raul Pertierra, Jane Vincent). London: Palgrave, 172-188.

Hiller, Harry, Franz, Tara (2004). New Ties, Old Ties and Lost Ties: The Use of the Internet in Diaspora. New Media \& Society 6/6, 731-752.

Hunter, Alistair (2015). Empowering or Impeding Return Migration? ICT, Mobile Phones and Older Migrants' Communications with Home. Global Networks 15/4, 485-502.

Jordan, Tim (1999). Cyberpower: The Culture and Politics of Cyberspace and the Internet. London: Routledge.

King, Russell (2012). Theories and Typologies of Migration: An Overview and a Primer Willy Brandt Series of Working Papers in International Migration and Ethnic Relations 3/12, https://www.researchgate.net/publication/260096281/download (21. 12. 2018).

Khorshed, Alam, Imran, Sophia (2015). The Digital Divide and Social Inclusion among Refugee Migrants: A Case in Regional Australia. Information Technology and People 28/2, 344-365.

Kluzer, Stefano, Gabriel, Rissola (2009). E-Inclusion Policies and Initiatives in Support of Employability of Migrants and Ethnic Minorities in Europe. Information Technologies and International Development 5/2, 67-76.

Kozachenko, Ivan (2013). Horizon Scanning report: ICT and Migration. Working Papers of the Communities \& Culture Network,https://www.abdn.ac.uk/socsci/ documents/ICT_and_Migration_main.pdf (15.12. 2018).

Lee, Rainie, Wellman, Barry (2012). Networked: The New Social Operating System. Cambridge, Massachusetts: The MIT Press.

Lenarčič, Blaž (2010). Socialni kapital v virtualnih skupnostih. Koper: Univerzitetna založba Annales.

Lenarčič, Blaž (2010a). Sociabilnost posameznikov med teritorialno in omrežno organizacijo družbe. Teorija in praksa: Revija za družbena vprašanja 47/2-3, 454-468. Lenarčič, Blaž (2014). Vpliv informacijsko-komunikacijskih tehnologij na velikost socialnih omrežij v kontekstu lokalno-globalnih dinamik. Teorija in praksa: Revija za družbena vprašanja 5, 285-308.

Licoppe, Christian, Smoreda, Zbigniew (2006). Rhytms and Ties: Towards a Pragmatics of Technologically Mediated Sociability. Computers, Phones and the Internet: Domesticating Information Technologies (ur. Robert Kraut, Malcolm Brynin, Sara Kiesler). Oxford: University Press, 296-314.

Lingel, Jessa, Naaman, Mor, boyd, dannah (2014). City, Self, Network: Transtnational Migrants and Online Identity Work. Geographic Distance 15-19, 1502-1510.

Madianou, Mirca, Miller, Daniel (2012): Polymedia: Towards a New Theory of Digital Media in Interpersonal Communication. International Journal of Cultural Studies 16/2, 169-187. 
Massey, Douglas idr. (1998). Worlds in Motion: Understanding International Migration at the End of the Millenium. Oxford: Clarendon Press.

Meden, Ahac (2007). Spletne strani Slovencev po svetu. Dve domovini / Two Homelands $26,47-73$.

Meyrowitz, Joshua (1985). No Sense of Place: The Impact of Electronic Media on Social Behavior. Oxford: University Press.

Milharčič Hladnik, Mirjam (2017). Internet in preobrazbe ohranjanja kulturne dediščine $v$ slovenskoameriških etničnih skupnostih. Dve domovini / Two Homelands $28,57-72$.

Mikola, Maša, Gombač, Jure (2008). Internet kot medij ohranjanja narodne in kulturne dediščine med Slovenci po svetu: Stare dileme novih rešitev. Dve domovini / Two Homelands 28, 39-56.

Mlinar, Zdravko (1997). Globalizacija kot izziv za sociološko raziskovanje. Teorija in praksa 33/4, 575-595.

Mlinar, Zdravko (1994). Individuacija in globalizacija v prostoru. Ljubljana: SAZU.

Nedelcu, Mihaela (2012). Migrants' New Transnational Habitus: Rethinking Migration through a Cosmopolitan Lens in the Digital Age. Journal of Ethnic and Migration Studies 38/9, 1339-1356.

Nimo Ilhan, Ali (2016). Going on Tahriib the Causes and Consequences of Somali Youth Migration to Europe. Published by the Rift Valley Institute, https://www.refworld. org/docid/57e92d114.html (26.6. 2018).

Oblak, Tanja, Petrič, Gregor (2005). Splet kot mediji in mediji na spletu. Ljubljana: Fakulteta za družbene vede.

Portes, Alejandro (2001). Introduction: The Debates and Significance of Immigrant Transnationalism. Global Networks 1/3, 181-193.

Portes, Alejandro, Guarnizo, Luis, Landolt, Patricia (1999). The Study of Transnationalism: Pitfalls and Promise of an Emergent Research Field. Ethnic and Racial Studies 22/2, 217-237.

Putnam, Robert (2000). Bowling Alone: The Collapse and Revival of American Community. New York: Simon \& Schuster.

Robertson, Zoe, Wilding, Raelene, Gifford, Sandra (2016). Mediating the Family Imaginary: Young People Negotiang Absence in Transnational Refugee Families. Global Networks: A Journal of Transnational Affairs 16/2, 219-236.

Sedmak, Mateja, Zadel, Maja (2015). (Mešane) kulturne identitete. Annales: Series historia et sociologia 25/1, 155-170.

Smith, Michael (2001). Transnational Urbanism: Locating Globalization. Massachusetts: Blackwell.

Terranova, Tiziana (2004). Network Culture: Politics for the Information Age. London: Pluto Press.

Trček, Franc (2003): Problem informacijske (ne)dostopnosti. Ljubljana: Center za prostorsko sociologijo, FDV. 
Tsuda, Takeyuki (2012). "Whatever Happened to Simultaneity? Transnational Migration Theory and Dual Engagement in Sending and Receiving Countries." Journal of Ethnic and Migration Studies 38/4, 631-649.

Vancea, Mihaela, Boso, Alex (2014). Connected Immigrants? Four Methodological Challenges for the Analysis of ICT Use through Survey Data. Migraciones Internacionales 7/3, 44-71.

Welsch, Wolfgang (2001). Transculturality: The Changing Form of Cultures Today. Filozofski vestnik 22/2, 59-86.

Wellman, Barry (2001). Physical Place and Cyberplace: The Rise of Personalized Networking. International Journal of Urban and Regional Research 25, 227-252.

Wellman, Barry (2000). Changing Connectivity: A Future History of Y2.03K. Sociological Research Online 4/4, http://www.socresonline.org.uk/4/wellman.html (24. 10. 2018).

Zavratnik, Simona, Cukut Krilić Sanja (2018): Digital Routes, "Digital Migrants": From Empowerment to Control over Refugees' Digital Footprints. Družboslovne razprave XXXIV/89, 143-163.

Zelenik, Marijana (2018). Raba družbenih medijev med mladimi migranti z območja nekdanje Jugoslavije. Mladi in mediji. Zbornik SUBKULTURE: Prispevki za kritiko in analizo družbenih gibanj (ur. Andrej Neterer). Maribor: Kulturni center, zavod za umetniško produkcijo in založništvo, 123-152.

Zhao, Shanyang (2003). Toward a Taxonomy of Copresence. Presence 12/5, 445-455, http://astro.temple.edu/ bzhao001/Taxonomy_Copresence.pdf (12. 9. 2019).

Zijlstra, Judith, van Liempt, Ilse (2017). Smart(phone) Travelling: Understanding the Use and Impact of Mobile Technology on Irregular Migration Journeys. International Journal Migration and Border Studies 3/2, 174-191. 


\section{SUMMARY}

\section{THE MIGRATION PROCESS IN THE NETWORK SOCIETY Blaž LENARČIČ}

In the first part of the article, the author presents the concept of a network society, in which relationships and processes are based on network principles. In this context, particular attention is paid to the action of individuals that is independent of time and place, which is a key feature of the network society. At an experiential level, such action allows the world to be perceived as smaller or more manageable, meaning that individuals have the possibility of interconnecting beyond territorial and national borders, which has important effects on the migration process. In the second part of the article, the author focuses on the study of the use of information and communication technologies in the migration context. In addition to the fact that such research has only begun to develop rapidly in the last decade, the author notes that certain changes are needed in explaining the contemporary migration process, which must go beyond interpretations related to the context of physical distance. In this sense, the author argues that information and communication technologies are an inseparable part of contemporary (developed) society, and just as the current economic, political and cultural spheres cannot be understood without considering the technological dimension, the same goes for understanding the migration process. On this basis, the author presents the individual phases of the migration process (pre-migrant, travel, post-migrant and established phase) and the role and use of information and communication technologies in each of them, which among other things demonstrates that this is a rather broad and diverse field of research. At the same time, it shows that these technologies significantly change the migration experience and, consequently, influence the understanding of the very concept of migrant. 